Case Reports
in Dermatology

\title{
Primary Cutaneous Cryptococcosis: An Unusual Injection Site Infection
}

\author{
Guy Shalom ${ }^{a, b}$ Amir Horeva, c \\ ${ }^{a}$ Faculty of Health Sciences, Ben-Gurion University of the Negev, Beer-Sheva, Israel; \\ ${ }^{\mathrm{b}} \mathrm{Clalit}$ Health Services, Tel-Aviv, Israel; 'Pediatric Dermatology Service, Soroka University \\ Medical Center, Beer-Sheva, Israel
}

\section{Keywords}

Cutaneous cryptococcosis · Immunosuppression · Infections · Amphotericin-B · Injection site infection · Fluconazole

\begin{abstract}
Primary cutaneous cryptococcosis (PCC) is an uncommonly reported entity. We describe an unusual case of PCC in an injection site of an immunocompromised patient. The specific case demonstrates a challenging treating dilemma with different alternative treatment choices. In the presented clinical setting, each choice concealed its risks and benefits. We highlight the importance of patient education for taking the appropriate measures for the disinfection of subcutaneous injection sites.

(C) 2020 The Author(s)

Published by S. Karger AG, Basel
\end{abstract}

\section{Introduction}

Cryptococcosis is a common opportunistic infection that largely affects immunocompromised patients, either as a subacute or chronic disease. The organism initially affects the respiratory tract, and from there dissemination can occur to other organs such as the skin (in up to $15 \%$ of cases [1]), the central nervous system, and other organs [2]. Although cryptococcosis commonly affects HIV-infected patients, other patients with chronic immunosuppression might be infected as well [3, 4]. Two species are frequently isolated: Cryptococcus neoformans and Cryptococcus gattii. C. neoformans is a microorganism found in decaying woods or 


\section{Case Reports in Dermatology}

Case Rep Dermatol 2020;12:138-143

DOI: $10.1159 / 000508783$

C 2020 The Author(s). Published by S. Karger AG, Basel www.karger.com/cde

Shalom and Horev: Primary Cutaneous Cryptococcosis

fruits and bird droppings (especially from pigeons) and has a worldwide distribution [5]. C. neoformans affects mostly patients with impaired cell-mediated immune response, classically HIV infected patients, posttransplant patients, and those on corticosteroid therapy. In contrast, $C$. gattii species are distributed in a more limited geographic manner, isolated from decomposing woods in tropical and subtropical areas and eucalyptus trees [6]. Moreover, C. gattii seems to be more virulent and affects immunocompetent as well as immunocompromised patients $[5,7,8]$. Cutaneous cryptococcosis, in the setting of systemic disease, is usually caused by hematogenous dissemination in patients with severe disease or with deep immunodepression. In contrast to the systemic disease, primary cutaneous cryptococcosis (PCC) is a distinct clinical entity [2], caused by direct inoculation to the skin, and has no other systemic involvement. Cutaneous findings may include papulonodules, ulcers, pyoderma gangrenosum-like, and cellulitis-like [3]. PCC is a diagnosis of exclusion: positive culture for Cryptococcus spp. with no evidence of systemic disease, skin lesions are observed, and the involvement of other organs must be ruled out [9]. Some authors add other criteria, such as a unilesional disease confined to a certain body area and positive history of previous exposure to trauma or contaminated source $[10,11]$.

PCC was first described and distinguished from the cutaneous dissemination of a systemic infection in 1928 [12] and has been rarely reported since, making this entity controversial in its very beginning. However, this reality was true only until recently. In 1984, while PCC was still a controversial entity, Sussman et al. [13] reported a patient with cutaneous cryptococcosis without evidence of visceral involvement at the time of diagnosis and during 5 years of follow-up. The authors concluded that cutaneous cryptococcosis does not always signify systemic disease, hence recognizing PCC as a different disease. During the past recent years, PCC has been reported more commonly, both in immunocompromised and immunocompetent patients [14-16]. The increasing emergence of patients with mild chronic immunosuppression is causing PCC to be more and more relevant. We herein report a case of PCC in a young female, demonstrating an unusual injection site infection. In addition, we discuss the uniqueness and complexity of handling such an infection in a chronically immunocompromised individual with multiple background comorbidities.

\section{Case Report}

A female in her 30s was admitted to our department following the appearance of cutaneous ulcers on her right thigh of 2 months' duration. The rest of the physical examination was unremarkable. Her past medical history included cirrhosis due to autoimmune hepatitis and myelodysplasia. Regular medications included azathioprine (Imuran ${ }^{\circledR}$ ), prednisone $15 \mathrm{mg} /$ day, and subcutaneous erythropoietin derivative (Aranesp ${ }^{\circledR}$ ). The ulcers were located on the erythropoietin derivative injection sites. The patient was unemployed and owned several birds and pigeons, placed in cages situated on the roof of her house.

Physical examination revealed a deep ulcer, $4.5 \mathrm{~cm}$ in diameter, with central eschar, sharp, undermined borders, and surrounding purple hue, resembling pyoderma gangrenosum. Next to it were noted a 1-cm pending ulcer and a purple cellulitis-like macule of 8-9 cm with ill-defined borders (Fig. 1a, b).

Histopathologic examination demonstrated an extensive inflammatory infiltrate composed of mononuclear cells, giant cells, and plasma cells (Fig. 2a, b). Periodic acid-Schiff highlighted central yeast forms (Fig. 2c). Visualization of the characteristic thick capsule was done by mucicarmine staining (Fig. $2 \mathrm{~d}$ ). 


\section{Case Reports in Dermatology}

Case Rep Dermatol 2020;12:138-143

DOI: $10.1159 / 000508783$

(c) 2020 www.karger.com/cde

Shalom and Horev: Primary Cutaneous Cryptococcosis

Laboratory workup revealed mild anemia, mild leukopenia, and mildly elevated liver function tests; all were consistent with baseline blood tests performed during the past year. All other ancillary tests, including total body computed tomography and lumbar puncture, ruled out other systemic involvement. Wound cultures on Sabouraud dextrose agar at $37^{\circ} \mathrm{C}$ $\left(98.6^{\circ} \mathrm{F}\right)$ demonstrated $C$. neoformans var. neoformans.

Treatment with intravenous amphotericin-B, $0.7 \mathrm{mg} / \mathrm{kg} / \mathrm{day}$, was initiated. Four days later, severe bone marrow suppression, refractory hypokalemia, hypomagnesemia, and drug fever developed. Those findings were linked to the systemic treatment with amphotericin-B, and the treatment was switched to fluconazole $400 \mathrm{mg}$ once daily. Several days after this treatment the fever subsided, and blood counts and electrolytes returned to their baseline values. Three weeks after initiating treatment with fluconazole the skin ulcers had improved dramatically, and the cellulitis-like lesion was absorbed (Fig. 1c). After 6 weeks of treatment, complete clinical and cultural resolution was achieved and the treatment was completed.

\section{Discussion}

During the past recent years, the incidence of PCC has been on the rise, with increasingly frequent reports. Marques et al. [17] described 11 patients diagnosed with PCC with circumscribed lesions on their upper limbs. Six of the patients were mildly immunosuppressed due to low-dose corticosteroid therapy. Most lesions were infiltrative or tumoral with up to $40 \mathrm{~cm}$ in diameter. Fluconazole up to $400 \mathrm{mg} /$ daily was the main therapeutic regimen and proved to be efficient. In 2008, Jasch et al. [18] described a case of PCC presenting as a pyoderma gangrenosum-like lesion. The patient was a 66-year-old hobby pigeon breeder, chronically immunosuppressed due to daily prednisolone treatment for his systemic lupus erythematosus. Ferry et al. [19] reported in 2011 a case of PCC in a liver transplant recipient with a pyoderma gangrenosum-like lesion [19]. The case described here is typical and straightforward concerning the clinical diagnosis; the patient is a passionate pigeon breeder, and the skin lesion developed where she injects her erythropoietin. Immunosuppression was caused by an autoimmune disease (autoimmune hepatitis, chronic myelodysplasia) and medications (prednisone and azathioprine). Each alternative treatment choice that could have been taken into account with our patient concealed its clinical challenge. The presence of drug-related immunosuppression concomitant with chronic myeloid dysplasia necessitated systemic treatments in order to avoid systemic dissemination. As the patient had active autoimmune hepatitis, with evident ongoing liver damage and cirrhosis, the first treatment choice was amphotericin-B, which has minimal liver toxicity compared with other available treatments. Nevertheless, bone marrow suppression and severe electrolyte disturbances prompted switching to fluconazole, which eventually proved to be more beneficial and safer, despite its liver-related adverse reaction.

In conclusion, we present a case of PCC, an entity with an increasing prevalence in the presence of mildly chronic immunosuppression. In the setting of immunosuppression, patient education for taking the appropriate measures for the disinfection of subcutaneous injection sites is warranted. 


\section{Case Reports in Dermatology}

\begin{tabular}{l|l}
\hline Case Rep Dermatol 2020;12:138-143 \\
\hline DOI: $10.1159 / 000508783$ & $\begin{array}{l}\text { ( ) 2020 The Author(s). Published by S. Karger AG, Basel } \\
\text { www.karger.com/cde }\end{array}$ \\
\hline
\end{tabular}

Shalom and Horev: Primary Cutaneous Cryptococcosis

\section{Acknowledgment}

The authors thank Prof. Sima Halevy for her contribution and involvement in the management of this case.

\section{Statement of Ethics}

The patient gave written informed consent for publication of her case (including publication of images). The research was conducted ethically in accordance with the World Medical Association Declaration of Helsinki.

\section{Conflict of Interest Statement}

The authors have no conflicts of interest to declare.

\section{Funding Sources}

None.

\section{Author Contributions}

G. Shalom collected the data and wrote the initial manuscript draft. A. Horev evaluated and revised the manuscript and is the corresponding author. Both authors provided critical feedback and contributed to the final version of the manuscript.

\section{References}

1 Du L, Yang Y, Gu J, Chen J, Liao W, Zhu Y. Systemic review of published reports on primary cutaneous cryptococcosis in immunocompetent patients. Mycopathologia. 2015 Aug;180(1-2):19-25.

2 Neuville S, Dromer F, Morin O, Dupont B, Ronin 0, Lortholary O; French Cryptococcosis Study Group. Primary cutaneous cryptococcosis: a distinct clinical entity. Clin Infect Dis. 2003 Feb;36(3):337-47.

3 Chiriac A, Mares M, Mihaila D, Solovan C, Moldovan C, Stolnicu S, et al. Primary cutaneous cryptococcosis during infliximab therapy. Dermatol Ther (Heidelb). 2017 Jan;30(1):e12405.

4 Noguchi H, Matsumoto T, Kimura U, Hiruma M, Kusuhara M, Ihn H. Cutaneous cryptococcosis. Med Mycol J. 2019;60(4):101-7.

5 Li SS, Mody CH. Cryptococcus. Proc Am Thorac Soc. 2010 May;7(3):186-96.

6 Lazéra MS, Cavalcanti MA, Trilles L, Nishikawa MM, Wanke B. Cryptococcus neoformans var. gattii evidence for a natural habitat related to decaying wood in a pottery tree hollow. Med Mycol. 1998 Apr;36(2): 119-22.

7 MacDougall L, Fyfe M, Romney M, Starr M, Galanis E. Risk factors for Cryptococcus gattii infection, British Columbia, Canada. Emerg Infect Dis. 2011 Feb;17(2):193-9.

8 Lacaz CS, Heins-Vaccari EM, Hernandez-Arriagada GL, Martins EL, Prearo CA, Corim SM, et al. Primary cutaneous cryptococcosis due to Cryptococcus neoformans var. gattii serotype $\mathrm{B}$, in an immunocompetent patient. Rev Inst Med Trop São Paulo. 2002 Jul-Aug;44(4):225-8.

9 Ng WF, Loo KT. Cutaneous cryptococcosis - primary versus secondary disease. Report of two cases with review of literature. Am J Dermatopathol. 1993 Aug;15(4):372-7.

10 Pau M, Lallai C, Aste N, Aste N, Atzori L. Primary cutaneous cryptococcosis in an immunocompetent host. Mycoses. 2010 May;53(3):256-8. 


\section{Case Reports in Dermatology}

\begin{tabular}{l|l}
\hline Case Rep Dermatol 2020;12:138-143 \\
\hline DOI: 10.1159/000508783 & $\begin{array}{l}\text { ( 2) 2020 The Author(s). Published by S. Karger AG, Basel } \\
\text { www.karger.com/cde }\end{array}$ \\
\hline
\end{tabular}

Shalom and Horev: Primary Cutaneous Cryptococcosis

11 Patel P, Ramanathan J, Kayser M, Baran J Jr. Primary cutaneous cryptococcosis of the nose in an immunocompetent woman. J Am Acad Dermatol. 2000 Aug;43(2 Pt 2):344-5.

12 Buschke A, Joseph A. Blastomycosis. In: Jadassohn J, editor. Handbuch der Haut und Geschlechtskrankheiten. Vol. II. Berlin: Springer; 1928.

13 Sussman EJ, McMahon F, Wright D, Friedman HM. Cutaneous cryptococcosis without evidence of systemic involvement. J Am Acad Dermatol. 1984 Aug;11(2 Pt 2):371-4.

14 Allegue F, de Lis MP, Pérez-Alvarez R. Primary cutaneous cryptococcosis presenting as a whitlow. Acta Derm Venereol. 2007;87(5):443-4.

15 Moosbrugger EA, Adams BB, Kralovic SM. Cutaneous cryptococcosis in a patient on corticosteroid therapy for rheumatoid arthritis. Int J Dermatol. 2008 Jun;47(6):630-2.

16 Sun HY, Alexander BD, Lortholary O, Dromer F, Forrest GN, Lyon GM, et al.; Cryptococcal Collaborative Transplant Study Group. Cutaneous cryptococcosis in solid organ transplant recipients. Med Mycol. 2010 Sep;48(6):785-91.

17 Marques SA, Bastazini I Jr, Martins AL, Barreto JA, Barbieri D’Elia MP, Lastória JC, et al. Primary cutaneous cryptococcosis in Brazil: report of 11 cases in immunocompetent and immunosuppressed patients. Int J Dermatol. 2012 Jul;51(7):780-4.

18 Jasch KC, Hermes B, Scheller U, Harth W. Pyoderma gangrenosum-like primary cutaneous cryptococcosis. Acta Derm Venereol. 2008;88(1):76-7.

19 Ferry T, Moos D, Radenne S, Bienvenu AL, Kanitakis J. Primary cutaneous cryptococcosis in a liver transplant recipient. BMJ Case Rep. 2011 Jun;2011:bcr0220113814.
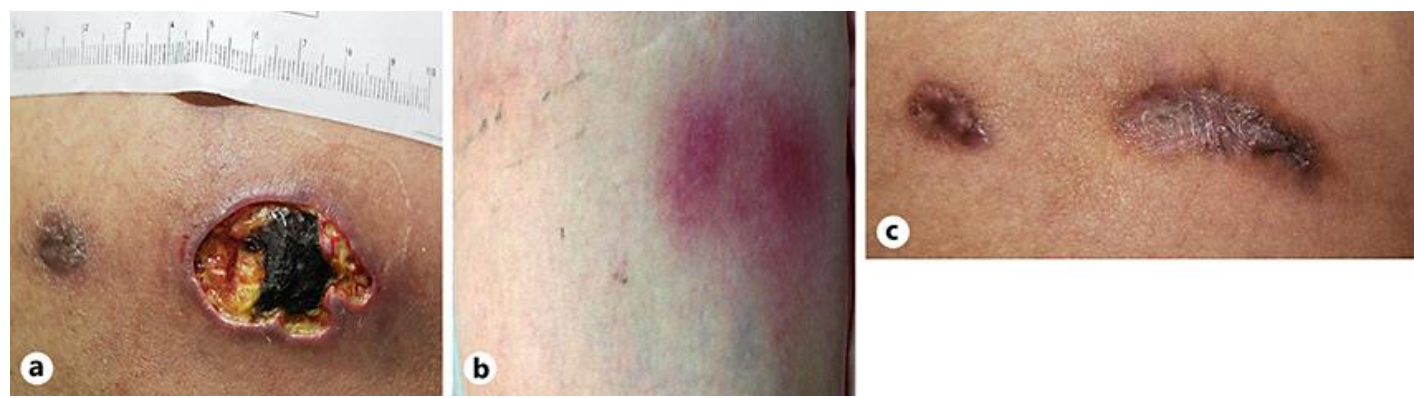

Fig. 1. Typical cutaneous lesions of primary cutaneous cryptococcosis. The patient demonstrated a 4.5-cm ulcer, resembling a pyoderma gangrenosum next to a smaller pending ulcer on the anterior aspect of the right thigh (a), a cellulitis-like lesion on the posterior aspect of the right thigh (b), and significant improvement following 4-week treatment with fluconazole (c). 


\section{Case Reports in Dermatology}
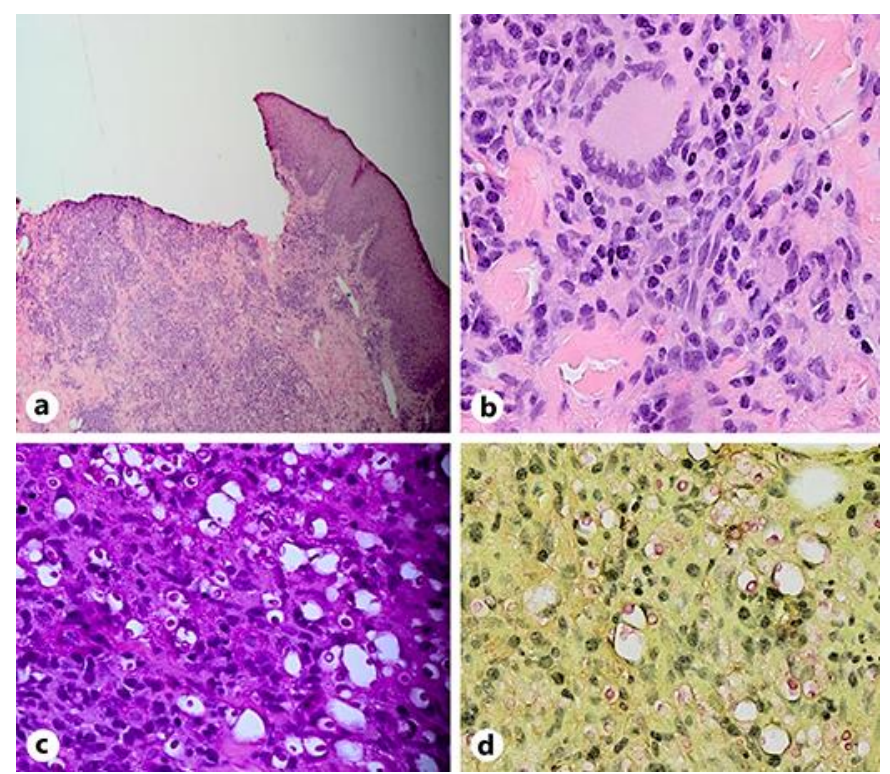

Fig. 2. Histopathologic examination, 5-mm punch biopsy from ulcer margins. H\&E, periodic acid-Schiff, and mucicarmine staining demonstrated deep ulceration with dense infiltration (H\&E, magnification $\times 40)(a)$, infiltrate composed of plasma cells and giant cells $(H \& E$, magnification $\times 360)(b)$, periodic acid-Schiff staining demonstrating encapsulated fungus (magnification $\times 360)(c)$, and mucicarmine staining demonstrating encapsulated fungus (magnification $\times 360)(d)$. 